\title{
A Novel Chaotic Switched Modulation for EMI Suppression in Electrical Drive System
}

\author{
Mehmet Emin Asker and Hasan Kurum
}

\begin{abstract}
In electric drive systems common mod voltage (CMV) is known as voltage between power line and ground. CMV causes negative effects on both electric engine and its driver whereas switching operation occurs in power devices. In addition switching frequency and its multiples in CMV cause electromagnetic and aqustic noises. In this paper a novel FixedFrequency chaotic switched sinusoidal pulse width modulation (FFCS-SPWM) is proposed. The cruial point in proposed FFCSSPWM method is to obtained a new carrier wave by summation of carrier wave and its inverse form. In FFCS-SPWM method extra switching loses were reduced due to constant switching frequency. This method also applied to permanent magnet synchronous motor (PMSM) vector control system. The reduction of electromagnetic interference (EMI), aqustic noises and dv/dt stress effects that occur in CMV is simulated by proposed method. Moreover SPWM combined with chaoticfrequency chaotic switched (CFCS) is proposed to reduce the differential mode voltage (DMV) which occurs due to voltage between lines. Finally in this method switching frequency change chaotically and also in this paper it shown that, CFCS-SPWM provides to reduce EMI, aqustic noises which are caused by CMV and DMV.
\end{abstract}

Index Terms - Common Mod Voltage, Chaotic swiching, Elektromagnetic interference (EMI), Acoustic noise

\section{INTRODUCTION}

$\mathrm{C}$ MV AND DMV have some bad effects on PWM voltage based inverter. DMV can damage engine windings or reduce engine life under condition of immediately change occurs in high frequency inverter voltage. On the other hand chance occurs in CMV, causes leakage current between engine shaft and ground due to immediately change in CMV that provide electrostatic coupling between stator and rotor. These leakage currents that have high amplitude damages grounding system and causes EMI in transmission line. In addition coupling effect and leakage current that is in engine bearing cause physical disruption in motor bearing. The immediately

MEHMET EMIN ASKER, is with vocational school of technical sciences of dicle University, Diyarbakir, Turkey (e-mail: measker@dicle.edu.tr).

iD https://orcid.org/0000-0003-4585-4168

HASAN KÜRÜM, is with Department of Electrical-Electronics Engineering of Firat University, Elazig, Turkey, (e-mail: hkurum@firat.edu.tr )

iD https://orcid.org/0000-0002-5498-6819

Manuscript received January 9, 2021; accepted May 25, 2021.

DOI: $10.17694 /$ bajece. 857247 change occurs due to switching frequency of inverter. Therefore voltage causes harmonics that create EMI and acoustic noises in switching frequency and its multiples [1-9]. The harmonics that are in the interval of (9-150) $\mathrm{KHz}$ known as EMI, whereas (6-20) $\mathrm{KHz}$ called as audible acoustic noise. Especially the harmonics between $6-12 \mathrm{KHz}$ create noises that disturb ears. The solution for mentioned problem is not increasing switching frequency because it causes loses [8-14].

Switching of power devices causes to change in voltage and current in a short time that creates EMI. The establishments related with electromagnetic compatibility (EMC) specify some limitation about EMI. An electrical equipment or devices must have certificate of conformity which provided by these establishments [15-17].

To avoid the bad effects of CMV and DMV several methods were improved such as increasing switching frequency, suitable filter design. Filter design can be solution for harmonics, however it has drawback in terms of cost, volume and weight [15].

To reduce the harmonics amplitude of CMV and DMV spreading of amplitude in an interval which known as modulation technics [15-25] are used to avoid the negative effects of CMV, DMV and acoustic noises[16-17]. These modulation technics known as random and chaotic modulation.

Moreover in lower switching frequency case especially engine/motor with a low leakage inductance has high current harmonic components that causes vibration, noise and loses [21].

There are various paper reduction of EMI and acoustic noise with modulation method in AC drive systems [9-14]. Random modulation methods are improved to suppress EMI [18-24,29]. Due to spreading harmonic in these methods. They provide reduction in acoustic noises and mechanical vibration.

Random PWM can be realized as method such as random frequency switching, random pulse position technic and random switching [18]. On the other hand SPWM and space vector (SV) modulation can be employed to realize random modulation. There some paper about reduction of EMI and acoustic noise by using random PWM technics [23-24,30].

Another problem appears in electrical driver is noises occurs during motor operation. These acoustic noises are caused by magnetic, mechanical, aerodynamics or electronic effects [10].

The noises based on electronic effects appears due to switching frequency in power converters. In Inverter based AC driver switching frequency causes to undesirable problems such as switching loses vibration, momentum ripple and EMI. Acoustic noises especially below $20 \mathrm{KHz}$ are disturbing for 
ears. Random or chaotic PWM modulation is usually applied to induction motor. However for PMSM driver researches are limited. On the other hand the papers focused on chaotic modulation that, is applied to PMSM driver, are rare [1014,23,31].

PSMS becomes to compete with induction motor in terms of volume, efficiency and lifetime coast. Recently they become popular in air and sea transport [32]. Especially in surface mounted PMSM motor has a lower phase inductance than induction motors. Therefore, PMSM affects EMI more than induction motor [30].

Inspire the chaotic modulation methods improved from random modulation methods. Chaotic signal can be obtained and applied easier than random signal because random signals are obtained from different circuits by help of algorithm [24].

There are some methods about chaotic modulation in literature. These are known as chaotic pulse position PWM, hybrid chaotic SPWM and SV-PWM [15-17,29]. The chaotic methods are applied to induction motor driver and obtained reduction in EMI, acoustic noises and mechanical vibration by Zheng [16-17].

In this paper for PMSM vector controlled driver a novel constant frequency chaotic switched FFCS-SPWM method and chaotic frequency chaotic switched CFCS-SPWM methods is proposed. In this method it is shown that with the advantage of constant switching frequency EMI and acoustic noises due to CMV are reduced.

Although this method is successful to reduce CMV negative effects, it is not successful to reduce DMV based noise. Therefore CFCS- SPWM method is improved to show reduction of noises that are based on DMV. The effects of method is shown by using power density comparison of CMV and DMV.

In this study, conventional SPWM, chaotic switching frequency PWM (CSPWM), random switching frequency SPWM (RSPWM), FFCS-SPWM, CFCS- SPWM, fixedfrequency random Switched (FFRS) SPWM and randomfrequency random switched (RFRS) SPWM were compared.

In literature, generally random bits are obtained by shift registers in random switching methods. This proposal method only one D type flip-flop is used to obtain random bits. The feature of the method is reduced the complexity of the method and unnecessary elements requirement. Furthermore first time in this paper the bits that are obtained by D type flip flop is used for inverter modulation.

\section{EFFECTS OF CMV AND DMV ON DRIVER SYSTEMS}

CMV is the potential difference between the midpoint of DC inverter's bus and star point of load. This value is dependent to inverter output voltage. The output voltage of inverter is formed by pulse which its average value is sinusoidal wave. The frequencies that except basic frequency is known as harmonic and these frequencies causes undesirable effects on motor. Especially due to sudden sharp rising and falling in voltage high frequency harmonics occurs in switching operation. This harmonic also causes to damage seriously both on motor and driver circuit. In lower switching frequency motors whose leakage inductances are small and its harmonics in current are high cause vibration, noise and loses. Therefore switching frequency increases in range of switching loses are allowed. In $\mathrm{KW}$ power applications switching frequency is selected interval between $3-25 \mathrm{KHz}[21]$.

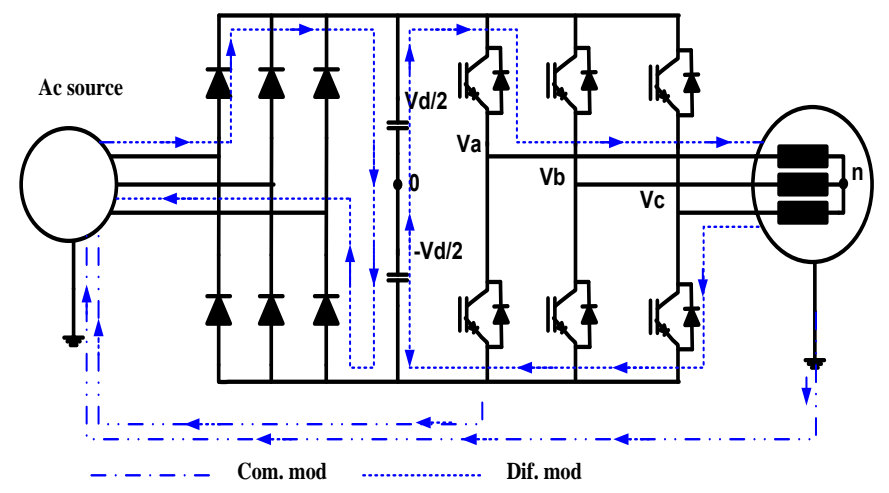

Fig. 1. Effects of CMV and DMV on AC drivers system

Using figure $1 \mathrm{CMV}$ and DMV can be computed from equation (1-2)

$$
\begin{aligned}
& V_{C M}=V_{n \mathrm{0}}=\left(V_{a \mathrm{0}}+V_{b 0}+V_{c 0}\right) / 3 \\
& V_{D M}=V_{i 0}-V_{j 0},(i, j=a, b, c)
\end{aligned}
$$

\section{Proposed ChaOtic Modulation Methods}

\section{A. Chaotic Switching Frequency}

In most of chaotic modulation methods it is need a chaotic switching frequency or a carrier triangle wave whose period is changed chaotically in specific interval. To make frequency chaotic in equation (4) chaotic map variable is used [15-16, 24].

In literature and also in this paper to make a frequency chaotic logic map is used. In these maps depends of parameters system behaves periodic or in some case it behaves as chaotic. The logic map that is given in equation (3) behaves as chaotic in case A changes in interval of (3, 57-4).

In this paper $\mathrm{A}$ is taken as 3,9

$X_{n+1}=A X_{n}\left(1-X_{n}\right)$

$f=f_{0}+X_{n} \Delta f \sin \left(2 \pi f_{m} t\right)$

$f$ is real switching frequency $f_{0}$ is fixed switching frequency $\Delta f$ the amount of change in frequency, $f_{m}$ frequency of modulation. $X_{n}$ is chaotic map variable

\section{B. Chaotic Bit}

Chaotic bits can be obtained from a chaotic map or an oscillator. Chaotic maps can be in one or two dimension. The variable of one dimension maps is a sign that varies in the interval of [0-1]. It varies interval of [(-1)-(1)] in two dimension maps. The chaotic bits in sampling period can be obtain in case where chaotic map variables match with a reference value or two obtained signal as a chaotic map performs in two different star point.

\section{Carrier Wave with Chaotic Period}

The switching frequency is same as frequency of carrier triangle wave. Therefore the frequency of carrier triangle wave 
can be changed chaotically as switching frequency changes chaotically. The carrier triangle wave can be obtained in different ways. For example in each 0.25 period of wave an equation constructs and then they can be combined to obtain triangle wave equation or identify method can be employed. Equation $(6,18)$ can be employed to obtain triangle wave. In this paper carrier wave is obtained from equation (4). Equation (5) and (6) is also used to obtain carrier wave [16].

$$
\begin{aligned}
& V_{t}=\frac{2}{\pi} \arcsin (\sin (X)) \\
& X=\int_{-\infty}^{t}\left[2 \pi f_{0}+2 \pi \Delta f X_{n} \sin \left(\int_{-\infty}^{t} 2 \pi f m d t\right) d t\right]
\end{aligned}
$$

\section{FFCS-SPWM Method}

The aim of to improve a novel constant switching frequency method it is easy to used in application. In FFCS-SPWM a carrier wave that has a constant switching frequency and its negative (reverse/inverse) form and with help of $2 \times 1$ multiplexer it is matched with reference wave. Selected control signal is obtained from random bit generator. The output wave is carrier wave as random bit generator output is 1 otherwise it is reverse form of carrier wave. Thus a new carrier wave is obtained by help of random switching frequency. By comparing this new carrier wave with the reference wave, the inverter control signal (PWM) is obtained.

In this method, chaotic bits obtained with the help of logistic maps are obtained. Then these chaotic bits are transformed into random bits at the carrier wave frequency with the help of D-type flip flops. This method is illustrated in fig 2 .

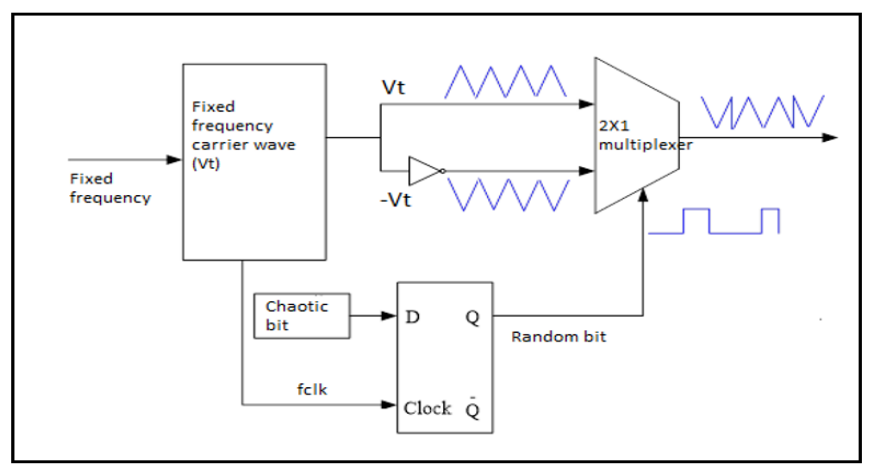

Fig. 2. The principal scheme of FFCS- SPWM method

\section{E. CFCS-SPWM Method}

In this method a new method is formed from carrier wave frequency which is made chaotic. In this method switching frequency change chaotically. It means carrier wave period change chaotically. In DSP applications, it is difficult to apply CFCS-SPWM because its frequency changes chaotically [24]. However, it can be applied as open and closed loop to DSP and FPGA applications where the switching frequency is variable. The principal CFCS-SPWM method scheme is given in fig. 3

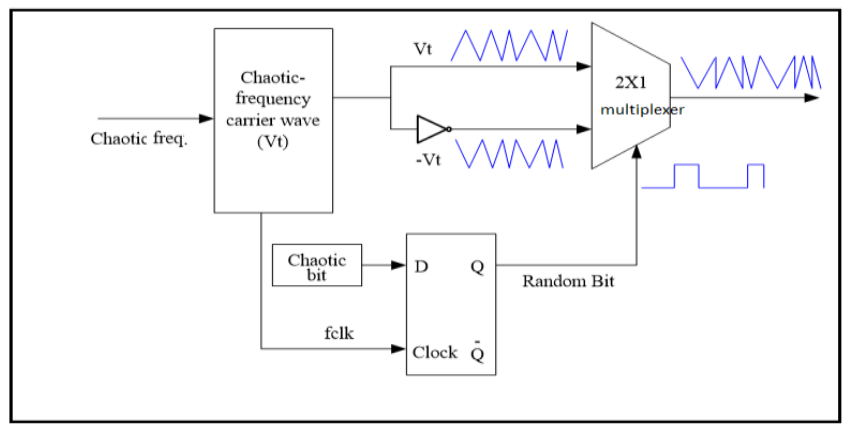

Fig. 3. The principal scheme of CFCS-SPWM method

IV. Simulation Results

The simulations were done by matlab-simulink. In this research simulation were done for c conventional SPWM, CSPWM (logistic map), FFCF-SPWM (logistic map), FFRSSPWM (random signal,) CFCS-SPWM (logistic map) and RFRS-SPWM (random signal). For power spectrum matlab periodogram was used.

In simulation it is compared the effect of proposal method for CMV and DMV in view of reduction of EMI and acoustic noises. For EMI the power spectral density of VCM and VDM was investigate.

The result obtained from PSD is in the acceptable range (9150) KHz. It is allowed in country by VDE[16-17].

Acoustic noise can be analysed in the frequency that is below $20 \mathrm{KHz}$. However interval of (6-12) $\mathrm{KHz}$ in power spectrum that disturbs ears can informed clearly for acoustic noise [16-17]. In addition the negative effects of harmonics that occurs in CMV are analysed in interval of $(0-25) \mathrm{KHz}$ which the negative effect of harmonic is reduced. In simulation used motor has 5N.m loaded and $63 \mathrm{Rad} / \mathrm{s}$ reference velocity and for each method CMV and DMV power spectral density is obtained.

All discussion is made for EMI between intervals of 9-150 $\mathrm{kHz}$ over max PSD value. The amplitude of harmonic is indicated the amplitude of EMI.

In figure 4 the CMV power spectrum is obtained and the result shows that it is $19 \mathrm{~dB} / \mathrm{Hz}$ for SPWM, $0 \mathrm{~dB} / \mathrm{Hz}$ for CSPWM , $0 \mathrm{~dB} / \mathrm{Hz}$ for FFCS-SPWM, $2 \mathrm{~dB} / \mathrm{Hz}$ for FFRSSPWM, $-5 \mathrm{~dB} / \mathrm{Hz}$ for CFCS-SPWM, $-1 \mathrm{~dB} / \mathrm{Hz}$ for RFRSSPWM. Moreover form VDM result that are given in fig.5. it is $18 \mathrm{~dB} / \mathrm{Hz}$ for SPWM, $9 \mathrm{~dB} / \mathrm{Hz}$ for CSPWM, $17 \mathrm{~dB} / \mathrm{Hz}$ for FFCS-SPWM, $17 \mathrm{~dB} / \mathrm{Hz}$ FFRS-SPWM, $5 \mathrm{~dB} / \mathrm{Hz}$ for CFCSSPWM, $8 \mathrm{~dB} / \mathrm{Hz}$ for RFRS-SPWM. These values of the methods are given in Table II.

The CMV analyses show that the performance of FFCSSPWM is better than the performance of conventional fixed frequency SPWM and FFRS-SPWM. However for all methods CFCS-SPWM shows the best performance. The result shows proposal methods are successful in reduction EMI.

Furthermore for acoustic noise the interval of (0-12) $\mathrm{KHz}$ was analyzed in figure 4 . For that interval of $(0-12) \mathrm{KHz}$ CMV is $39 \mathrm{~dB} / \mathrm{Hz}$ for SPWM, $19 \mathrm{~dB} / \mathrm{Hz}$ for CSPWM, 13 $\mathrm{dB} / \mathrm{Hz}$ for FFCS-SPWM, $12 \mathrm{~dB} / \mathrm{Hz}$ for FFRA-SPWM, 10 $\mathrm{dB} / \mathrm{Hz}$ for CFCS-SPWM, $12 \mathrm{~dB} / \mathrm{Hz}$ for RFRS-SPWM. The result of VDM in figure 5 . It is $18 \mathrm{~dB} / \mathrm{Hz}$ for SPWM, 10 $\mathrm{dB} / \mathrm{Hz}$ for CSPWM, $17 \mathrm{~dB} / \mathrm{Hz}$ for FFCS-SPWM, $17 \mathrm{~dB} / \mathrm{Hz}$ 
for FFRS-SPWM, $\quad 5 \mathrm{~dB} / \mathrm{Hz}$ for CFCS-SPWM, $7 \mathrm{~dB} / \mathrm{Hz}$ for RFRS-SPWM. These values of the methods are given in Table II.

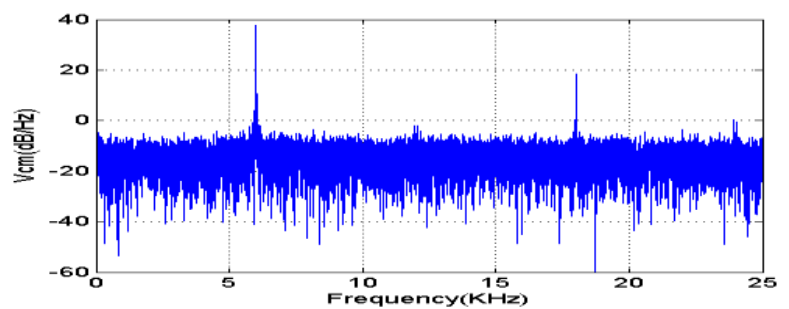

a)

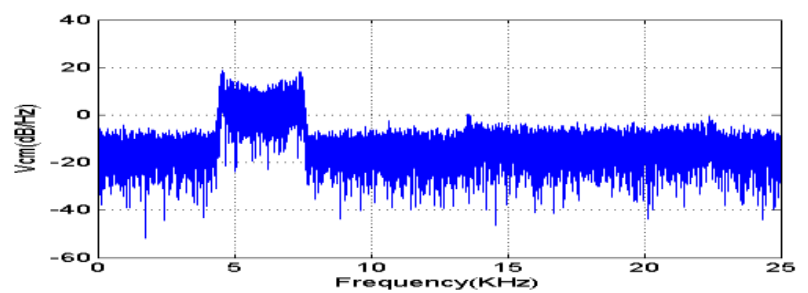

b)

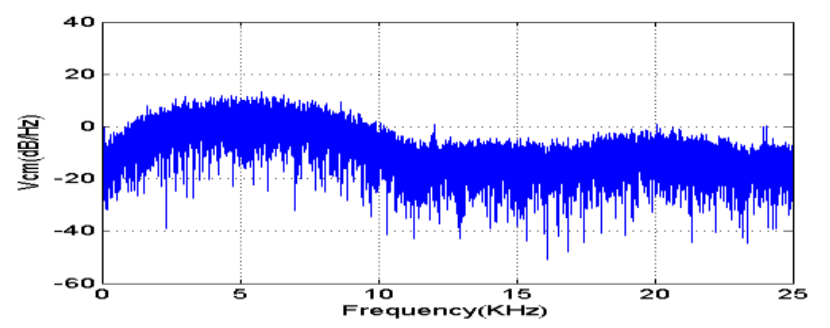

c)

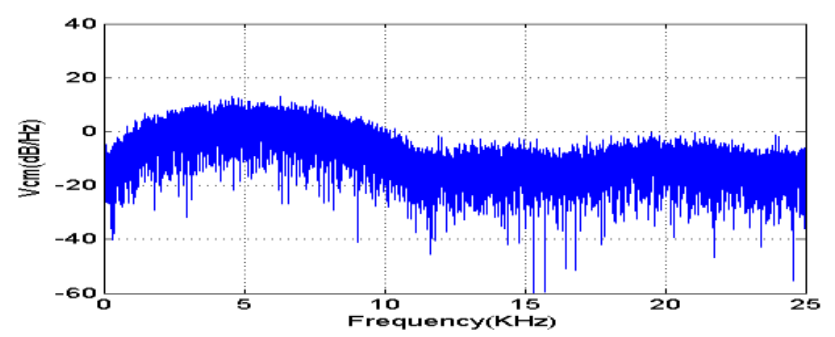

d)

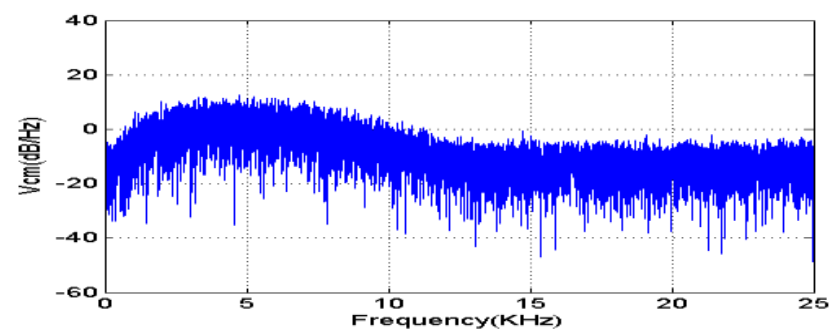

e)

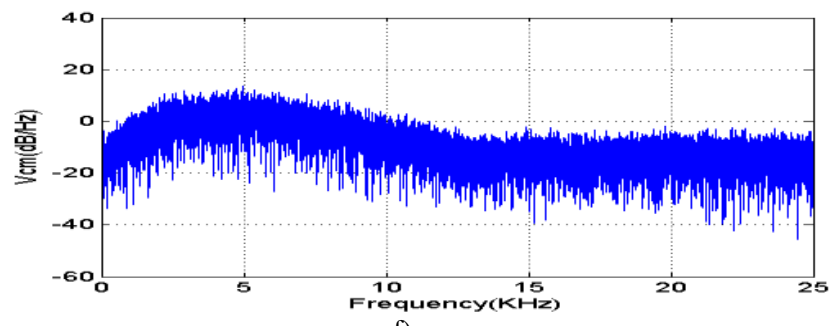

f)

Fig. 4. Power Spectral Density for $V_{\mathrm{cm}}(\mathrm{CMV})$ a) SPWM b) CSPWM (logistic map) c) FFCS-SPWM (logistic map) d) FFRS-SPWM (random signal) e) CFCS-SPWM (logistic map) f) RFRS-SPWM (random signal)

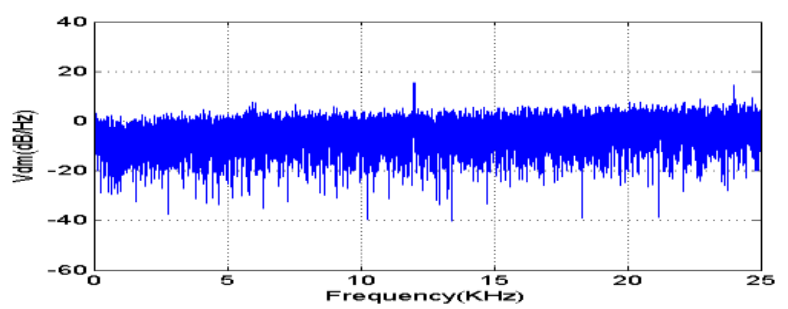

a)

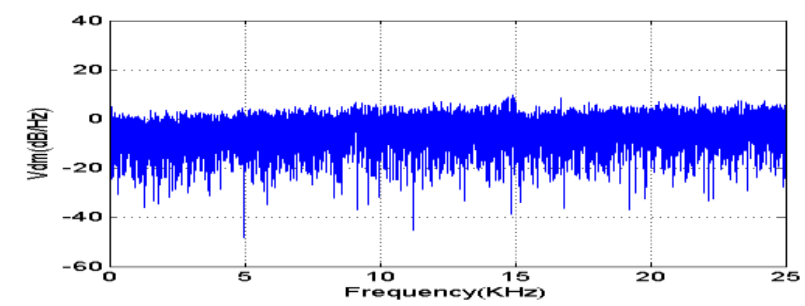

b)

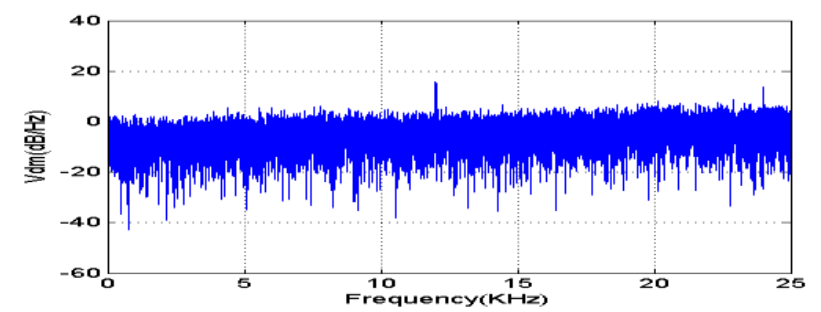

c)

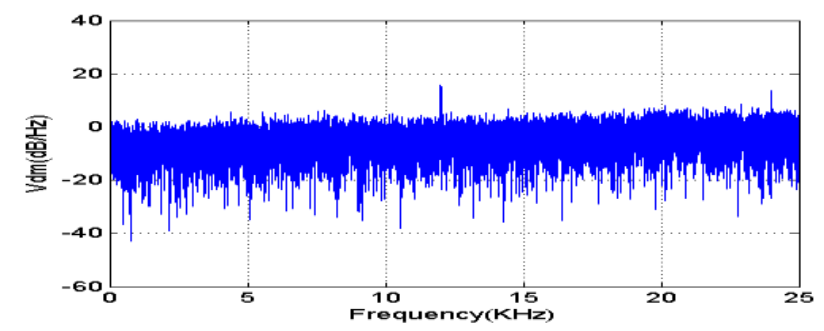

d)

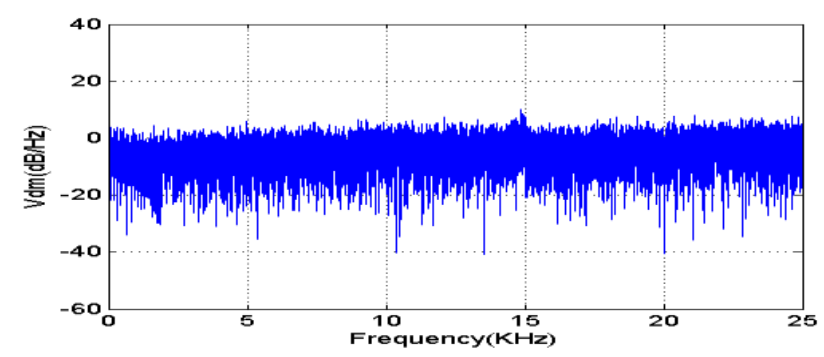

e)

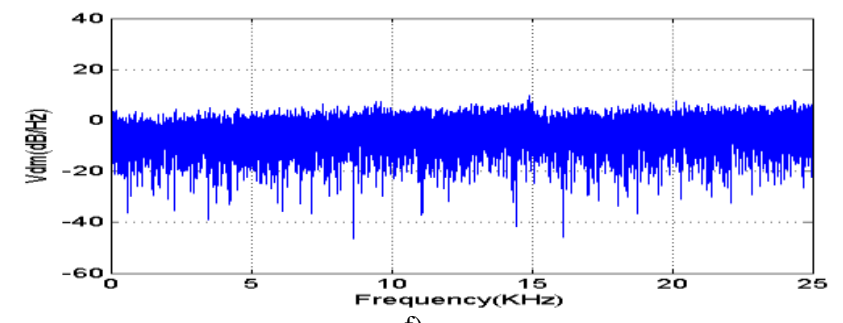

f)

Fig. 5. Power Spectral Density for $V_{d m}$ (DMV) a) SPWM b) CSPWM(logistic map) c) FFCS-SPWM (logistic map) d) FFRSSPWM(random signal) e) CFCS-SPWM (logistic map) f) RFRS-SPWM (random signal) 
The result show the proposal methods are successful in reduction acoustic noise and the best result is obtained in CFCS-SPWM method.

Finally the proposal methods are succesful enough for CMV which is know resans of harmonics that spreads to reduce their amplitude by the proposal methods.

TABLE I.

MOTOR PARAMETERS

\begin{tabular}{|l|l|l|l|}
\hline $\mathrm{R}_{\mathrm{s}}$ & $0.41 \Omega$ & $\mathrm{J}$ & $0.0222 \mathrm{Kgm}^{2}$ \\
\hline $\mathrm{L}_{\mathrm{d}}$ & $6.8 \mathrm{mH}$ & $\mathrm{B}$ & $0 \mathrm{Nms} / \mathrm{rad}$ \\
\hline $\mathrm{L}_{\mathrm{q}}$ & $6.8 \mathrm{mH}$ & $\mathrm{U}_{\mathrm{N}}$ & $220 \mathrm{~V}$ \\
\hline $\mathrm{P}$ & 2 & $\mathrm{~K}_{\mathrm{T}}$ & $0.653 \mathrm{Nm} / \mathrm{A}$ \\
\hline
\end{tabular}

TABLE II

EMI AND ACOUSTIC NOISE OF METHODS

\begin{tabular}{|c|c|c|c|c|c|}
\hline \multirow{2}{*}{\multicolumn{2}{|c|}{ METHODS }} & \multicolumn{2}{|c|}{$\begin{array}{c}\text { Common Mod } \\
\text { Voltage (Vcm) } \\
\text { (PSD) }\end{array}$} & \multicolumn{2}{|c|}{$\begin{array}{c}\text { Differential } \\
\text { Mode Voltage } \\
(\mathrm{Vdm}) \\
(\mathrm{PSD})\end{array}$} \\
\hline & & $\begin{array}{c}\text { EMI } \\
(\mathrm{dB} / \mathrm{Hz})\end{array}$ & $\begin{array}{l}\text { Acoustic } \\
\text { noise } \\
(\mathrm{dB} / \mathrm{Hz})\end{array}$ & $\begin{array}{c}\text { EMI } \\
(\mathrm{dB} / \mathrm{Hz} \\
)\end{array}$ & $\begin{array}{c}\text { Acoust } \\
\text { ic } \\
\text { noise } \\
(\mathrm{dB} / \mathrm{Hz} \\
) \\
\end{array}$ \\
\hline \multirow{4}{*}{$\begin{array}{l}\text { Fixed } \\
\text { Frequ } \\
\text { ency }\end{array}$} & SPWM & 19 & 39 & 18 & 18 \\
\hline & CSPWM & 0 & 19 & 9 & 10 \\
\hline & $\begin{array}{l}\text { FFCS- } \\
\text { SPWM }\end{array}$ & 0 & 13 & 17 & 17 \\
\hline & $\begin{array}{l}\text { FFRS- } \\
\text { SPWM }\end{array}$ & 2 & 12 & 17 & 17 \\
\hline \multirow{2}{*}{$\begin{array}{l}\text { Chaot } \\
\text { ic } \\
\text { Frequ } \\
\text { ency }\end{array}$} & $\begin{array}{l}\text { CFCS- } \\
\text { SPWM }\end{array}$ & -5 & 10 & 5 & 5 \\
\hline & $\begin{array}{l}\text { RFRS- } \\
\text { SPWM }\end{array}$ & -1 & 12 & 8 & 7 \\
\hline
\end{tabular}

\section{CONCLUSIONS}

In this paper method are proposed to reduce EMI and acoustic noises that are based switching frequency. In addition the reduction of effect of harmonics that are CMV based were analysed. The comparison that is based fixed switching frequency methods over CMV results show that the proposed FFCS-SPWM method has closer result to FFRS SPWM, but it has better result than FFRS-SPWM. The CFCS-SPWM method is the best proposal method due to result of simulations.

The result of chaotic and random method are closer. On the other hand the result of chaotic methods are better than the result of random methods. However the chaotic signal can be obtained more easier than random signal. These properties of chaotic method make them superior. In the chaotic method does not need filter due to reduce the effects of harmonics.

\section{REFERENCES}

[1] D. Jiang, F. Wang, and J. Xue, "PWM impact on CM noise and $\mathrm{AC}$ CM choke for variable-speed motor drives," IEEE Trans. Ind. Appl., vol. 49, no. 2, pp. 963972, Mar./Apr. 2013.

[2] C-.C. Hou, C-.C. Shih, P-.T. Cheng, and A. M. Hava, "Common-mode voltage reduction pulse width modulation techniques for three-phase grid connected converters," IEEE Trans. Power Electron. vol. 28, no. 4, pp. 1971-1979, Apr. 2013.

[3] J. Huang and H. Shi, "Reducing the common-mode voltage through carrier peak position modulation in an SPWM three-phase inverter," IEEE Trans. Power Electron., vol. 29, no. 9, pp. 4490-4495, Sep. 2014.

[4] J. W. Kimball and M. Zawodniok, "Reducing commonmode voltage in three-phase sine-triangle PWM with interleaved carriers," IEEE Trans Power Electron., vol. 26, no. 8, pp. 2229-2236, Aug. 2011.

[5] S. Kwak, and S.Mun, "Model Predictive Control Methods to Reduce Common-Mode Voltage for Three-Phase Voltage Source Inverters" IEEE Trans Power Electron., vol. 30, no. 9, pp. 5019-5034, Sep. 2015.

[6] M. C. Di Piazza, G. Tine, and G. Vital, "An improved active common mode voltage compensation device for induction motor drives," IEEE Trans. Ind. Electron., vol. 55, no. 4, pp. 1823-1834, Apr. 2008.

[7] J. Huang and H. Shi, "A Hybrid Filter for the Suppression of Common-Mode Voltage and DifferentialMode Harmonics in Three-Phase Inverters With CPPM," IEEE Trans. Ind. Electron., vol. 62, no. 7, pp. 3991-4000, Jul. 2015.

[8] L. Xing and J. Sun, "Conducted common-mode EMI reduction by impedance balancing," IEEE Trans. Power Electron., vol. 27, no. 3, pp. 1084-1089, Mar. 2012.

[9] D. Han, S. Li, Y. Wu, W. Choi and B. Sarlioglu, "Comparative analysis on conducted CM EMI emission of motor drives: WBG versus Si devices", IEEE Trans. Ind. Electron., vol. 64, no. 10, pp. 8353-8363, Oct. 2017.

[10] K. Borisov, T. E. Calvert, J. A. Kleppe, E. Martin, and A. M. Trzynadlowski, "Experimental investigation of a naval propulsion drive model with the PWM-based attenuation of the acoustic and electromagnetic noise," IEEE Trans. Ind. Electron., vol. 53, no. 2, pp. 450-457, Apr. 2006.

[11] Y. G. Jung, S. H. Na, Y. C. Lim, and S. H. Yang, "Reduction of audible switching noise in induction motor drives using random position space vector PWM," IEE Proc.-Electr. Power Appl., vol. 149, no. 3, pp. 195-200, May 2002.

[12] T. G. Habetler and D. M. Divian, "Acoustic noise reduction in sinusoidal PWM drives using a randomly modulated carrier," IEEE Trans. Power Electron., vol. 6, no. 3, pp. 356-363, Jul. 1991.

[13] J. A. Ferreira, P. Dorland, and F. G. de Beer, "An active inline notch filter for reducing acoustic noise in drives," IEEE Trans. Ind. Appl., vol. 43, no. 3, pp. 798-804, May/Jun. 2007.

[14]H. B. Ertan and N. Balkan, "Comparison of PWM and PFM induction drives regarding audible noise and vibration for household applications," IEEE Trans. Ind. Appl., vol. 40, no. 6, pp. 1621-1628, Nov./Dec. 2004.

[15]H. Li, Y.Liu, J.Lü, T. Zheng, and X. Yu, "Suppressing EMI in Power Converters via Chaotic SPWM Control Based on Spectrum Analysis Approach" IEEE Trans. Ind. Electron., VOL. 61, NO. 11,pp.6128-6136,2014.

[16]Z. Wang, K. T. Chau, and C. H. Liu, "Improvement of electromagnetic compatibility of motor drives using chaotic PWM," IEEE Trans. Magn., vol. 43, pp. 26122614, 2007. 
[17]Z. Zhang, K. T. Chau, Z. Wang, and W. Li, "Improvement of electromagnetic compatibility of motor drives using hybrid chaotic pulse width modulation," IEEE Trans. Magn., vol. 47, no. 10, pp. 4018- 4021,2011.

[18]R. L. Kirlin, S. Kwok, S. Legowski, and A. M. Trzynadlowski, "Power spectra of a PWM inverter with randomized pulse position" , IEEE Trans. Power Electron., vol. 9, no. 5,pp. 463-472, 1994

[19] K.S. Kim, Y.G. Jung, and Y.C. Lim, "A New Hybrid Random PWM Scheme" IEEE Trans. Power Electron., vol. 24, no. 1,pp.192-200, 2009

[20] S. Kaboli, J. Mahdavi, and A. Agah "Application of Random PWM Technique for Reducing the Conducted Electromagnetic Emissions in Active Filters" IEEE Trans. Ind. Electron, vol. 54, no. 4,pp.2333-2343,2007

[21]A. M. Hava, E Ün, "Performance Analysis of Reduced Common-Mode Voltage PWM Methods and Comparison With Standard PWM Methods for Three-Phase VoltageSource Inverters"' IEEE Trans. Power Electron ;vol. 24, no. 1,pp.241-252,2009

[22] Y.C. Lim, S.O. Wi, J.N. Kim, and Y.G. Jung "A Pseudorandom Carrier Modulation Scheme'" IEEE Trans. Pow. Electron; vol. 25, no. 4,pp.797-805,2010

[23] J.-Y. Chai, Y.-H. Ho, Y.-C. Chang, and C.-M. Liaw, “On acoustic noise reduction control using random switching technique for switch mode rectifiers in PMSM drive," IEEE Trans. Ind. Electron., vol. 55, no. 3, pp. 1295-1309, 2008.

[24] H. Khan, E. Miliani, and K. E. K. Drissi, "Discontinuous random space vector modulation for electric drives: A digital approach," IEEE Trans. Power Electron., vol. 27, no. 12 , pp. 4944-4951, 2012

[25]R. Gamoudi, D. Chariag and L. Sbita, "A review of spread spectrum based PWM techniques-A novel fast digital implementation", IEEE Trans. Power Electron., vol. 33, no. 12, pp. 10292-10307, Dec. 2018.

[26] G. Wang, L. Yang, G. Zhang, X. Zhang and D. Xu, "Comparative investigation of pseudorandom highfrequency signal injection schemes for sensorless IPMSM drives", IEEE Trans. Power Electron., vol. 32, no. 3, pp. 2123-2132, Mar. 2017.

[27] Sreej P, Muthukumar P, Padmasuresh L (2018) Boost up of random pulse width modulation over sinusoidal pulse width modulation for three phase voltage source inverter. Int J Pure Appl Math 119:407-429

[28] K. T. Chau and Z. Wang, Chaos in Electric Drive Systems-Analysis, Control and Application. Singapore: Wiley, 2011.

[29] H. Li, Z. Li, B. Zhang, F. Wang, N. Tan, and W. A. Halang, "Design of analogue chaotic PWM for EMI suppression," IEEE Trans. Electromagn. vol. 52, no. 4, pp. 1001-1007, 2010.

[30] Y. Xu , Q. Yuan , J. Zou and Y. Li "Analysis of triangular periodic carrier frequency modulation on reducing electromagnetic noise of permanent magnet synchronous motor" IEEE Trans. Magn., vol. 48, no. 11, pp. 44244427, 2012

[31] M.E.Asker, A.B. Ozer, H. Kurum, Reduction of EMI with chaotic space vector modulation in direct torque control. Elektronika ir Elektrotechnika 2016; 22 (1): 8-13.
[32]B. K. Bose, Power Electronics And Motor Drives: Advances and Trends, USA, elsevier,2006

\section{BIOGRAPHIES}

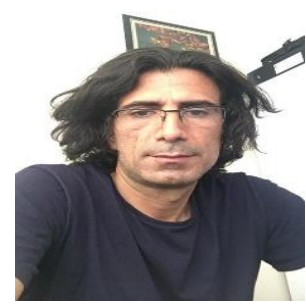

MEHMET EMIN ASKER was born in Diyarbakır, Turkey, in 1976. He received the B.S. degree in electrical electronics engineering, from Firat University, Elazig, Turkey in 1993, the M.S. degree and the Ph.D. degree in electrical machines, power electronics from Firat University, Elazig, Turkey, in 2009 and 2016, respectively. He is an Assistant Professor with Dicle University, Department of electrical power and energy. Where he teaches courses on power system, power electronics, circuit theory and electrical machines since 2007. His research interests include electrical machines, power electronics and power systems.

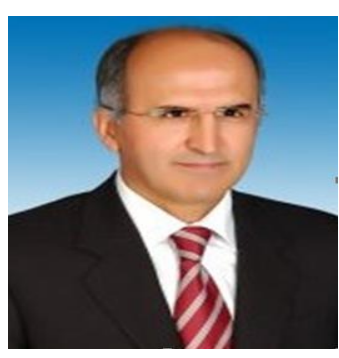

HASAN KURUM received the B.S., M.S., and Ph.D. degrees from Firat University (FU), Elazig, Turkey, in 1979, 1984, and 1990, respectively, all in electrical and electronics engineering. In 1997 and 2003, he became an Associate Professor and a Professor, respectively, at the Department of Electrical and Electronics Engineering, FU. He was also a Chief of Data Processing Center in 1997-2000 and 2004-2006 and a Founder Member and the Chief of Informatics Department at F.U. in 1990-2000 and 2002-2006. He designed the Infrastructure of Computer Data Processing and Computer Network. Between 2006 and 2009, he was the Dean of the Faculty of Communication. He completed Firat TV's new digital communication infrastructure and established Radio Firat. He was assigned as a Founder Dean at the Department of Engineering Faculty, Tunceli University, which was established in 2009. He is currently the Head of the Department of Electrical and Electronics Engineering, FU 